\title{
Beggars in rural areas: A socio-economic analysis
}

\author{
Dr. Jabir Hasan Khan, Dr. Menka, Shamshad \\ Associate Professor Department of Geography Aligarh Muslim University Aligarh-202002 \\ Department of Geography Aligarh Muslim University Aligarh-202002 \\ Research Scholar Department of Geography Aligarh Muslim University Aligarh-202002
}

\begin{abstract}
$\boldsymbol{A} \boldsymbol{B} \boldsymbol{S} \boldsymbol{T} \boldsymbol{R} \boldsymbol{A} \boldsymbol{C} \boldsymbol{T}$ : The present research paper is an attempt to analyse the spatial patterns of rural beggars' demographic characteristics, literacy, employment, income, household infrastructural facilities and their socioeconomic status. The study is based on primary source of data, collected through the field survey in the Aligarh district carried out during 2009 and altogether, 496 households of beggars were surveyed for the present study from the 70 villages of the district. Spatial analysis reveals the fact that the high level of demographic, literacy, employment, infrastructural facilities among rural beggars is witnessed in the peripheral parts of the district while, high level of per capita income is found in the central part of the study area. However, the overall analysis reveals the fact that the peripheral parts of the district are more developed than the central parts.

Key Words: Literacy Rate, Employment Rate, Per Capita Income, Household Infrastructural Facilities, SocioEconomic Status.
\end{abstract}

\section{Introduction}

Begging is viewed as a sign of growing poverty, or indigence, and as an occupation of last resort, but nonetheless as potentially linked to crime and illicit activities (ILO, 2004). “...public visibility of beggars is in direct contradiction to the dearth of information available about their lives" (Friends International, 2006). Begging is practiced to obtain means of survival from others what one is unable to get by oneself. This activity is a request directed to the rest of the society to bring oneself out of misery and poverty. In this regard, MOLSA (1992) defined begging as a method of earning one's living from the income obtained from other sectors of society being old age, poor health and lowest socio-economic conditions as a means of gaining sympathy. Most of the panhandlers or beggars live in poverty, 'panning' for a variety of reasons. Numerous sources point to support of alcohol and drug addictions as one of the major reasons for panhandling (Bodnarchuk et al., 2006; Bose and Hwang, 2002; Duneier, 1999; Lankenau, 1999; Addictions Foundation of Manitoba, 1996 \& 1993).

Beggary is a problem that is deep rooted in Indian culture. Religious faith has encouraged begging in India, believing that it is one way to please the Almighty. This has encouraged beggars to occupy footpaths and steps leading in religious places whether it is mosque and temple, especially during festive occasions. Of late, begging has become a profession since no physical and mental effort is required to earn one's bread. To gain the sympathy of the public, they adopt many tactics to collect more alms. The matter of begging is not the ignorable issue of the society, but in fact, the begging has become one of the most problematic social issues of India. It is, therefore, necessary that empirical studies have to be undertaken aimed at collecting relevant data on the subject.

A large volume of literature is available at national or international level on beggars in the urban areas but it lacks on beggars who live in the rural areas. There are lot of works in India regarding to the beggars of urban centre or areas (Kumarappa, 1945; Cama, 1945; Mukharjee, 1945; Gore, et al., 1959; Moorthy, 1959; Prasad: 1960; Ratan, 1961; Rao and Bogaert, 1970; Ramana and Rao, 1973; Jha, 1979; Pandian et al., 1979; DWCWAP, 1980; Das, 1983; Chaudhuri, 1987; Thirumalai et al., 2004; Goyal, 2005; Thakker et al., 2007; Mukherjee, 2008; Rafiuddin, 2008; Goel, 2010; Joshi and Singh, 2010) while, there were 6, 30,940 beggars and vagrants in India in 2001. Out of the total, 66 per cent beggars were in rural areas and 34 per cent in urban areas. Therefore, to know the overall image of the rural beggars, the present research work has been made to study the socio-economic status of the beggars who live in the rural parts of the Aligarh district of Uttar Pradesh, India.

\section{Aims and objectives}

The present study has been undertaken with the following specific objectives:

$\mathrm{i}$ to analyse the regional variations of the demographic characteristics, literacy, employment, per capita income, household infrastructural facilities among the rural beggars in Aligarh district.

ii to examine the spatial disparities in the socio-economic status of rural beggars in the study area. 


\section{Study area}

Aligarh district, a medium sized district, is spreading over an area of 3700.4 square kilometers in the Western part of Uttar Pradesh. It occupies the north-western part of the Uttar Pradesh which is fertile region of Ganga and Yamuna Doab. In the world map, the geographical location of this district is in North-Eastern Hemisphere and lying between the parallels of $27^{\circ} 29^{\prime}$ and $28^{\circ} 11^{\prime}$ north latitudes and meridians of $77^{\circ} 29^{\prime}$ and $78^{\circ} 38^{\prime}$ east longitudes. Its boundary touches the boundaries of five other districts (Bulandshahr, Badaun, Mathura, Hathras and Etah) of the Uttar Pradesh and one state (Haryana) of India. At present, the district is divided into five Tahsils namely, Koil, Khair, Gabhana, Atrauli and Iglas for the purpose of land record keeping, land revenue collection, judicial administration, etc. These tahsils are further sub-divided into 12 development blocks namely: Atrauli, Gangiri, Bijauli, Jawan, Chandus, Khair, Tappal, Dhanipur, Lodha, Akrabad, Iglas and Gonda.

According to 2001 Census, the district accommodates a residential population of 29, 92, 286 of which 29 per cent was classified as urban and 71 per cent as rural. The general density of population in the district was 820 persons per sq. $\mathrm{km}$. However, it was 607 persons per sq. $\mathrm{km}$. in the rural sector and 5,949 persons per sq. $\mathrm{km}$. in the urban sector. The general sex ratio that is the number of females per thousand males was 862 in the district, whereas, the figures for the rural and urban areas were 856 and 876 respectively. The literacy rate in the district is 58.5 per cent and the male literacy rate is 71.7 per cent and females are 43.0 per cent literate while, the percentage of literacy in rural and urban population was 56.5 and 63.2 respectively.

According to the Census of India there were 7,50,307 beggars and vagrants in India in 1981, which declined to 5,42,875 in 1991, though it further increased to $6,27,688$ in 2001. Out of the total beggars, about two third beggars were in rural areas while one-third in urban areas. The matter of begging is not the ignorable issue of the society, but in fact, the begging has become one of the most problematic social issues of India. It is, therefore, necessary that empirical studies have to be undertaken aimed at collecting relevant data on the subject.

\section{Database and methodology}

The study is based on primary source of data that has been collected the through field survey in the Aligarh district, carried out during 2009. The villages have been selected on the basis of stratified random sampling technique. According to 2001 Census, the district had 1210 revenue villages of which 1180 were inhabited. The inhabited villages were stratified into three categories based on the size of population, so that, all types of population and villages may get reasonable representation in the samples randomly drawn for the survey. Keeping in view the constraints of time and cost, it was decided to collect data for this enquiry from 6 per cent villages of each category. In this way 70 villages were selected for the survey, out of the 1180 inhabited villages, while, for the selection of households, 25 per cent beggars' households were randomly selected from each selected villages of the district. Altogether, 496 beggars' households were selected for the present study from the 70 villages of the district.

In the present analysis, a set of seventeen indicators of socio-economic development (vide Table 1) have been taken into account to determine the levels of socio-economic status of rural beggars at one hand and their employment rate and per capita income on the other hand in the twelve blocks of the district. These indicators fall into five categories like population characteristics, literacy, employment, income and household infrastructural facilities. In the first step, the raw data for each variable which determines the areal variations of selected variables and levels of their socio-economic status have been computed into standard score. It is generally known as Z value or Z-score. The score quantify the departure of individual observations, expressed in a comparable form. This means it becomes a linear transformation of the original data (Smith, 1973: 85). It may be expressed as:

$$
Z_{i j}=\frac{X_{i j}-\overline{X_{i}}}{\sigma_{i}}
$$

Where: $\quad Z_{i j}=$ Standardised value of the variable $i$ in block $j$,

$X_{i j}=$ Actual value of variable $i$ in block $j$,

$X_{i} \overline{\bar{M}}$ Mean value of variable $i$ in all blocks,

$\sigma_{i}=$ Standard deviation of variable $i$ in all blocks.

In the second step, the Z-scores of all variables have been added block wise and the average has taken out for these variables which may be called as composite score (CS) for each block and may be algebraically expressed as:

$$
C S=\frac{\sum Z_{i j}}{N}
$$


Where: $\quad C S$ stands composite score,

$\sum Z_{i j}$ indicates Z-scores of all variables $i$ in $\operatorname{district} j$,

$N$ refers to the number of variables.

The positive values relating to the districts' Z-score explain high level, while, negative values indicate the low level of socio-economic status in the study area.

Besides, advanced statistical techniques, GIS-Arc view programme (Version 3.2a) has been applied to show the spatial variations of population characteristics, literacy, employment, income and household infrastructural facilities of rural beggars, and their socio-economic status among the blocks of the Aligarh district through maps.

\section{Beggars' demographic characteristics}

The spatial pattern of demographic characteristics of rural beggars is shown in the Figure 2 and given in Table 1.The level of demographic characteristics varies from lowest -0.27 score in the Dhanipur block to the highest 0.77 score in the Gonda block of the district. The entire range of variations may be categorized into three grades such as high (above 0.17 score), medium ( 0.17 to -0.17 score) and low (below -0.17 score) (Table 3 ). The Figure 2 shows that the relatively high level of demographic characteristics are scattered in the district and they fail to form any region with the boundary adjacent blocks of the district. Three blocks (Bijauli, Chandaus and Iglas) come under the medium level of demographic characteristics and they are located in north-east, northwest and southern directions respectively. Six blocks of the district fall under the category of low level of demographic characteristics and all of them make a dominant region spreading over the blocks of Gangiri, Dhanipur, Lodha, Khair, Tappal and Jawan in the district.

\section{Beggars' literacy rate}

The Table 2 and the Figure 3 reveal that there is a wide regional variation in the levels of rural literacy rate in the district. The level of rural literacy varies from -0.77 score in the Jawan block to 0.89 score in the Akrabad block of the district. The entire range of variations may be grouped into three grades such as high (above 0.28 score), medium ( 0.28 to -0.28 score) and low (below -0.28 score). Only three blocks of the district experienced the high level (above 0.28 score) of literacy rate, in which, the blocks of Dhanipur and Akrabad make a small region in the south-eastern part, whereas, Gonda block fails to share with boundary of the neighboring blocks in the district. Five blocks with the z-score values of 0.28 to -0.28 belong to the medium level of literacy rate, wherein, Atrauli, Bijauli and Gangiri blocks constitute a remarkable region in the northeastern part but two blocks (Chandaus and Iglas) do not make any region the district. Four blocks of the district lie under the low level (below -0.28 score) of literacy rate which form a dominant region in the central part and western part of the district, comprising the blocks of Lodha, Khair, Tappal and Jawan.

\section{Beggars' employment rate}

The spatial pattern of the rural employment rate is shown in the Figure 4. The level of rural employment rate varies from the lowest -1.46 score in the Tappal block to the highest 1.56 score in the Gonda block of the district. The entire range of variation may be categorized into three grades such as high (above 0.48 score), medium ( 0.48 to -0.48 score) and low (below -0.48 score) (Table 2). Figure 4 shows that three blocks (Akrabad, Gonda and Atrauli) of the district have high employment rate and does not form any region in the district. They are widely scattered in the study area. Six blocks (Chandaus, Jawan, Lodha, Dhanipur, Bijauli and Gangiri) experienced medium level of rural employment rate and all of them form an interconnected extensive region central and eastern part of the district. Three blocks (Tappal, Khair and Gonda) of the district have the low level of rural employment rate and two of them make a small region in the north-western part of the district and one block does not form any region.

\section{Beggars' per capita income}

The rural per capita income is shown in the Table 2. The level of rural per capita income varies from 1.86 score in the Atrauli block to 1.32 score in the Gangiri block of the district. Figure 5 depicts that the six blocks namely, Lodha, Dhanipur, Gonda, Chandaus, Jawan and Gangiri have high level (above 0.50 score) of per capita income and form a large identifiable region in the whole central part of the district. Three blocks (Bijauli, Khair and Akrabad) experienced the medium level ( 0.50 to -0.50$)$ of per capita income and fail to share with the boundary of adjacent blocks of the district to form any region (Figure 5). Three blocks (Tappal, Iglas and Atrauli) of the district fall under the low level (below -0.50 score) of per capita income and do not form any region. 


\section{Beggars' household infrastructural facilities}

To measure the level of household infrastructural facilities, six variables have been chosen in the study area. They are $\mathrm{X}_{12}=$ own house, $\mathrm{X}_{13}=$ pucca house, $\mathrm{X}_{14}=$ drinking water facility available within their premises, $\mathrm{X}_{15}=$ bathroom facility available within their premises, $\mathrm{X}_{16}=$ latrine facility available within their premises and $\mathrm{X}_{17}=$ electricity facility available within their premises (Table 1 ). The development status in regard of rural household infrastructural facility is shown in the Figure 6. The level of rural household infrastructural facilities varies from -0.44 score in the Gonda block to 1.09 score in the Chandaus block of the district. The entire range of variations may be categorized into three grades i.e. high (above 0.23 score) medium ( 0.23 to -0.23 score) and low (below -0.23 score) as given in the Table 2. Figure 6 depicts that the two blocks (Chandaus and Iglas) experienced high level (above 0.23 score) of infrastructural facilities, do not form any region in the district. Five blocks of the district have the medium level $(0.23$ to -0.23 score) of infrastructural facilities and four blocks of them (Khair, Lodha, Dhanipur and Akrabad) form a dominant region in the central part of the district and the Bijauli block of the district does not form any region. Five blocks of the district come under the low level (below - 0.23 score) of infrastructural facilities, three of them, make a dominant region in the north-eastern part of the district comprising the blocks of Jawan, Atrauli and Gangiri and remaining Tappal and Gonda blocks fail to share with the boundary of adjacent blocks of the district to form any region.

\section{Beggars' socio-economic status}

The level of socio-economic development of rural parts of the district varies from -0.83 score in the Tappal block to 0.62 score in the Gonda block of the district (Table 2). The Figure 7 depicts that four blocks have high level (above 0.20 score) of socio-economic development, two of them (Akrabad and Gangiri) make a small region in the south-eastern part of the district and remaining two blocks (Chandaus and Gonda) do not form any region. Four blocks with the z-score of 0.20 to -0.20 have the medium level of socio-economic development and three of them (Jawan, Lodha, and Dhanipur) form an identifiable region in the central part of the district and Bijauli block does not form any region. Four blocks of the district, namely, Tappal, Khair, Iglas and Atrauli fall under the low level (below -0.20 score) of socio-economic development, out of which, Tappal and Khair blocks make a small region in the western part of the district.

\section{Conclusion \& Suggestion}

The overall analysis of the study reveals that the central parts of the district have the low level of demographic characteristics and the peripheral parts witnessed the medium and high level of demographic characteristics The analysis of literacy rate of beggars depicts that the high level of literacy is experienced in the southern parts of the district, while, low level of beggars' literacy is observed in the central and western parts of the district.

The employment is found to be higher in the peripheral parts of the district, while, 60 per cent blocks of the district experienced medium level of employment rate situated in the central part of the district. The distribution analysis of per capita income shows that the whole central part of the district witnesses high level of per capita income. The spatial analysis of household infrastructural facilities reveals that the central part which runs north-west to south-east of the district fall under medium level of household infrastructural facilities and it found to be high in the western parts of the district. The analysis of socio-economic status reveals that beggars of the central blocks of the district experienced the medium level of socio-economic status, while, the peripheral blocks witnessed high as well low level of socio-economic status.

The rural beggars of the district are mainly involved in their ancestral activity i.e. begging for their survival having very low income and high dependency ratio. They have very little access to the educational opportunities and other modern household amenities and assets. Nevertheless, radio and cycle are the only assets which were mainly found within their households used for entertainment and transportation for begging purpose respectively. Thus, the rural areas of the district may be developed the other opportunities of work by promoting the agro, agro-allied and ancillary industries as animal husbandry, poultry, fisheries, horticulture, floriculture, dairy, piggery, apiculture, silviculture, sericulture etc. On the other hand, there should be an efficient implementation and diffusion of all the social and welfare schemes of rural development, launched by the Government of India for poverty alleviation, employment generation, development of educational and health infrastructure, basic amenities and facilities, etc. Surely, these measures will bring a light of hope for socioeconomic development of this marginalised population (beggars) in the rural areas of the Aligarh district (Khan, Shamshad and Hassan, 2011). 


\section{References}

[1]. Addictions Foundation of Manitoba, 1993. Change for the Better Program Statistical Report, Winnipeg.

[2]. Addictions Foundation of Manitoba, 1996. Change for the Better Program Statistical Report, Winnipeg.

[3]. Bodnarchuk, J., Patton, D. and Rieck, T., 2006. Adolescence without Shelter: A Comprehensive Description of Issues Faced by Street Youth in Winnipeg Addictions Foundation of Manitoba Winnipeg, Manitoba.

[4]. Bose, R. and Stephen, W.H., 2002. Income and spending patterns among panhandlers. Canadian Medical Association Journal 167 (5), 477-479.

[5]. Cama, K. H., 1945. Types of beggars. In J. M. Kumarappa (Ed.), Our Beggar Problem: How To Tackle It. Bombay: Padma Publications Ltd, 1-17.

[6]. Census of India, 2001. Primary Census Abstract, Series-1, Total Population: Table A-5. Registrar General and Census Commissioner, Govt. of India, New Delhi.

[7]. Chaudhuri, S., 1987. Beggars of Kalighat, Calcutta. Calcutta: Anthropological Survey of India, (MHRD).

[8]. Das, D. K. L., 1983. Evaluation of beggar problem in Tirupati. Social Defence, 19.

[9]. Duneier, M., 1999. Sidewalk, Farrar Straus and Giroux, New York.

[10]. DWCWAP, 1980. Profile of Beggars in Hyderabad City: A Socio-Economic Study. Andhra Pradesh: Indian Council of Social Welfare.

[11]. Friends International, 2006. The Nature and Scope of the Foreign Child Beggars Issue (Especially as Related to Cambodian Child Beggars) in Bangkok. UNIAP, p.3.

[12]. Goel, A., 2010. Indian anti-beggary laws and their constitutionality through the prism of fundamental rights with special reference to Ram Lakhan V. State. Asia Pacific Journal on Human Rights and the Law, 11(1), 23-38.

[13]. Gore, M.S., Mathur, J.S., Laljani, M.R. \& Takulia, H.S., 1959. The Beggar Problem in Metropolitan Delhi. Delhi: School of Social Work

[14]. Goyal, O.P., 2005. Anti-Social Pattern of Begging and Beggars. Gyan Publishing House.

[15]. International Labour Organisation, 2004. A Rapid Assessment of Bonded Labour in Domestic Work and Begging in Pakistan. Karachi: Collective for Social Science Research, p.20

[16]. Joshi, A. \& Singh, Y.P., 2010. Beggar. Research Abstracts on Social Defense and Trafficking Prevention (1998-2009), Documentation Centre for Women and Children, National Institute of Public Cooperation and Child Development New Delhi.

[17]. Khan, J., Shamshad and Hassan, T. 2011. Determinants of rural to urban migration of male population in India. Annals of the National Association of Geographers, India 31 (1), 51-65.

[18]. Kumarappa, J.M. (Ed)., 1945. Our Beggar Problem- How To Tackle It?. Bombay: Padma Publications Ltd.

[19]. Lankenau, S.E., 1999. Panhandling repertoires and routines for overcoming the non-person treatment. Deviant Behavior 20, 183206.

[20]. MOLSA, 1992. Study on Begging in Addis Ababa Action Oriented Addis Ababa, Ethiopia, p. 2.

[21]. Moorthy, M.V., 1959. Beggar Problem in Greater Bombay: A Research Study. Bombay: Indian Conference of Social Work.

[22]. Mukharjee, R., 1945. Causes of beggary. In J. M. Kumarappa (Ed.), Our Beggar Problem: How To Tackle It. Bombay: Padma Publications Ltd, 19-26.

[23]. Mukherjee, D., 2008. Laws for beggars, justice for whom: A critical review of the Bombay prevention of begging act 1959 . International Journal of Human Rights, 12(2), 279-288.

[24]. Pandian, S.R., Arul, F.V., George, K.V., Viswanathan, G., Amiruddin, P. \& Paramaguru, P., 1979. Police in the enforcement of social legislation symposium. Indian Journal of Criminology, 7, 179-204.

[25]. Prasad, L., 1960. Beggar problem in an Indian provincial town. The Indian Journal of Social Work, 21(2), 147-153.

[26]. Rafiuddin, M., 2008. Beggars in Hyderabad: A Study on Understanding the Economics of Beggary in Hyderabad; an Insight into Rehabilitation Possibilities. Andhra Pradesh: Hyderabad Council of Human Welfare.

[27]. Ramana, K.V. \& Rao, P.K., 1973. No option but beggary. Social Welfare, 19 (10), 13-14.

[28]. Rao, T.S., \& Bogaert, M.V.D., 1970. The beggar problem in Ranchi. The Indian Journal of Social Work, 31(3), 285-302.

[29]. Ratan, K., 1961. Beggar problem in Kanpur. The Indian Journal of Social Work, 21(4), 397-401.

[30]. Smith, D.M., 1973. The Geography of Social Well Being in the United State: An Introduction to Territorial Social Indicators. McGraw-Hill, New York, p. 85

[31]. Vikas Bhawan Office, Aligarh

[32]. Thakker, Y. Gandhi, Z., Sheth, H., Vankar, G.K. \& Shroff, S., 2007. Psychiatry morbidity among inmates of the beggar home. International Journal of Psychosocial Rehabilitation, 11(2), 31-36. 


\section{Appendices}

Table 1

List of the selected indicators of socio-economic development in Aligarh district, 2009

\begin{tabular}{|c|c|c|}
\hline Categories & Indicators & Definition \\
\hline \multirow{4}{*}{$\mathrm{DC}$} & $\mathrm{X}_{1}$ & Percentage of male population to the total selected population \\
\hline & $\mathrm{X}_{2}$ & Percentage of female population to the total selected population \\
\hline & $\mathrm{X}_{3}$ & Sex-Ratio \\
\hline & $\mathrm{X}_{4}$ & Household Size \\
\hline \multirow{3}{*}{ LR } & $\mathrm{X}_{5}$ & Total Literacy Rate \\
\hline & $\mathrm{X}_{6}$ & Male Literacy Rate \\
\hline & $\mathrm{X}_{7}$ & Female Literacy Rate \\
\hline \multirow{3}{*}{ ER } & $\mathrm{X}_{8}$ & Total Employment Rate \\
\hline & $\mathrm{X}_{9}$ & Male Employment Rate \\
\hline & $\mathrm{X}_{10}$ & Female Employment Rate \\
\hline PCI & $\mathrm{X}_{11}$ & Per Capita Income \\
\hline \multirow{6}{*}{$\mathrm{HF}$} & $\mathrm{X}_{12}$ & Percentage of households having own houses \\
\hline & $\mathrm{X}_{13}$ & Percentage of households living in pucca houses \\
\hline & $\mathrm{X}_{14}$ & Percentage of households having the drinking water facility within their premises \\
\hline & $\mathrm{X}_{15}$ & Percentage of households having bathroom facility within their premises \\
\hline & $\mathrm{X}_{16}$ & Percentage of households having latrine facility within their premises \\
\hline & $\mathrm{X}_{17}$ & Percentage of households having electricity facility within their premises \\
\hline
\end{tabular}

$\mathrm{DC}=$ Demographic Characteristics, LR= Literacy Rate, ER= Employment Rate, PCI= Per Capita Income, HF= Household Facilities, SED= Socio-Economic Development.

Table 2

Block-wise distribution of z-score of socio-economic development in Aligarh district, 2009

\begin{tabular}{|l|c|c|c|c|c|c|}
\hline Name of the block & DC & LR & ER & PCI & HF & SED \\
\hline Lodha & -0.26 & -0.33 & -0.42 & 1.06 & 0.09 & 0.03 \\
\hline Dhanipur & -0.27 & 0.78 & -0.24 & 0.62 & 0.03 & 0.18 \\
\hline Akrabad & 0.35 & 0.89 & 1.54 & -0.49 & 0.13 & 0.49 \\
\hline Gonda & 0.77 & 0.59 & 1.56 & 0.62 & -0.44 & 0.62 \\
\hline Iglas & 0.13 & 0.09 & -1.29 & -0.89 & 0.6 & -0.27 \\
\hline Khair & -0.24 & -0.49 & -0.62 & -0.38 & -0.02 & -0.35 \\
\hline Tappal & -0.25 & -0.76 & -1.46 & -1.25 & -0.43 & -0.83 \\
\hline Chandaus & 0.06 & -0.08 & -0.33 & 0.93 & 1.09 & 0.33 \\
\hline Jawan & -0.24 & -0.77 & 0.2 & 0.52 & -0.28 & -0.12 \\
\hline Atrauli & 0.23 & -0.08 & 0.87 & -1.86 & -0.37 & -0.24 \\
\hline Bijauli & 0.01 & 0.08 & -0.1 & -0.2 & -0.04 & -0.05 \\
\hline Gangiri & -0.23 & 0.03 & 0.27 & 1.32 & -0.34 & 0.21 \\
\hline Source: Calculiti
\end{tabular}

Source: Calculation is based on Sample Survey.

$\mathrm{DC}=$ Demographic Characteristics, $\mathrm{LR}=$ Literacy Rate, $\mathrm{ER}=$ Employment Rate, $\mathrm{PCI}=$ Per Capita Income, $\mathrm{HF}=$ Household Facilities, SED= Socio-Economic Development. 
Table 3

Levels of demographic characteristics, literacy rate, employment rate, household infrastructural facilities of rural beggars' and their socio-economic status in Aligarh district, 2009

\begin{tabular}{|c|c|c|c|}
\hline Category & Z-Score & No. of Block & Name of the Block \\
\hline \multicolumn{4}{|c|}{ Demographic Characteristics } \\
\hline High & Above 0.17 & 3 & Akrabad, Gonda and Atrauli \\
\hline Medium & 0.17 to -0.17 & 3 & Chandaus, Iglas and Bijauli \\
\hline Low & Below -0.17 & 6 & Lodha, Dhanipur, Jawan, Tappal, Khair and Gangiri \\
\hline \multicolumn{4}{|l|}{ Literacy Rate } \\
\hline High & Above 0.28 & 3 & Dhanipur, Akrabad and Gonda \\
\hline Medium & 0.28 to -0.28 & 5 & Iglas, Chandaus, Atrauli, Bijauli and Gangiri \\
\hline Low & Below -0.28 & 4 & Lodha, Jawan, Tappal and Khair \\
\hline \multicolumn{4}{|c|}{ Employment Rate } \\
\hline High & Above 0.48 & 3 & Akrabad, Gonda and Atrauli \\
\hline Medium & 0.48 to -0.48 & 6 & Lodha, Dhanipur, Jawan, Chandaus, Bijauli and Gangiri \\
\hline Low & Below -0.48 & 3 & Iglas, Tappal and Khair \\
\hline \multicolumn{4}{|c|}{ Per Capita Income } \\
\hline High & Above 0.50 & 6 & Lodha, Dhanipur, Jawan, Chandaus, Gonda and Gangiri \\
\hline Medium & 0.50 to -0.50 & 3 & Akrabad, Khair and Bijauli \\
\hline Low & Below -0.50 & 3 & Iglas, Atrauli and Tappal \\
\hline \multicolumn{4}{|c|}{ Household Facilities } \\
\hline High & Above 0.23 & 2 & Chandaus and Iglas \\
\hline Medium & 0.23 to -0.23 & 5 & Lodha, Dhanipur, Akrabad, Khair and Bijauli \\
\hline Low & Below -0.23 & 5 & Tappal, Gonda, Jawan, Atrauli and Gangiri \\
\hline \multicolumn{4}{|c|}{ Socio-Economic Development } \\
\hline High & Above 0.20 & 4 & Chandaus, Gonda, Akrabad and Gangiri \\
\hline Medium & 0.20 to -0.20 & 4 & Lodha, Dhanipur, Jawan and Bijauli \\
\hline Low & Below -0.20 & 4 & Tappal, Khair, Iglas and Atrauli \\
\hline
\end{tabular}

Source: Based on Table 2.

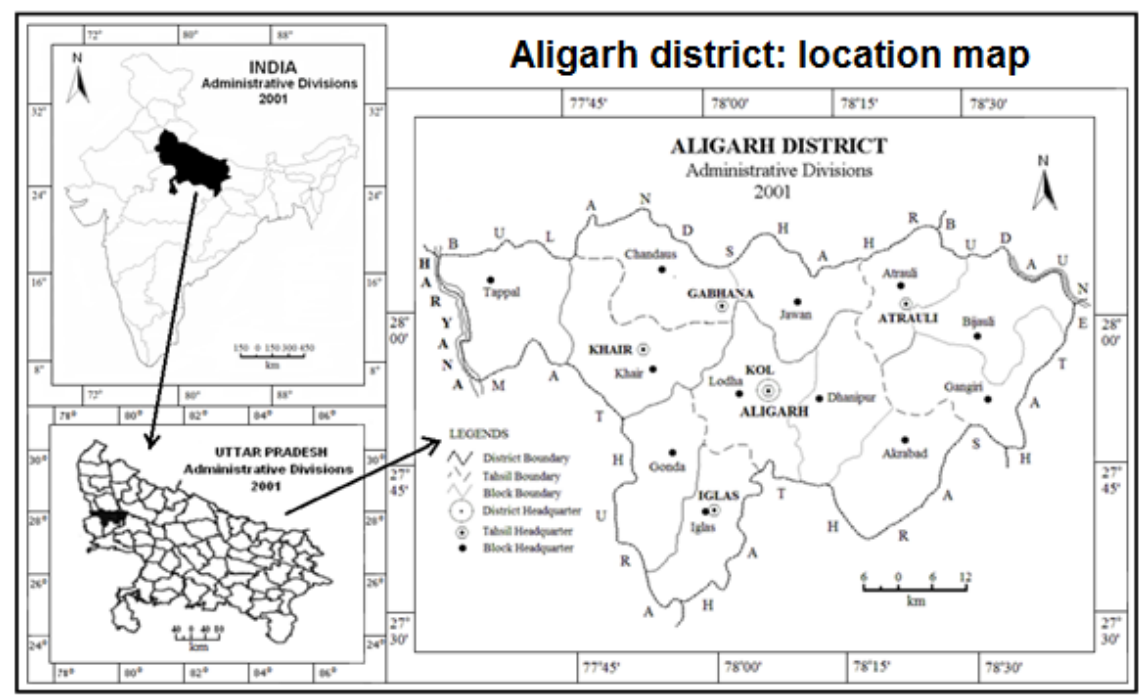

Source: Census of India and Vikas Bhavan, Aligarh, 2008

Figure 1 


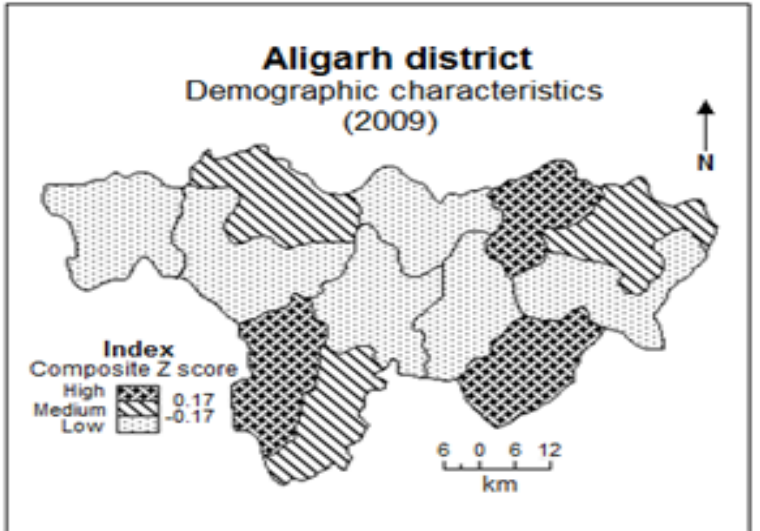

Figure 2

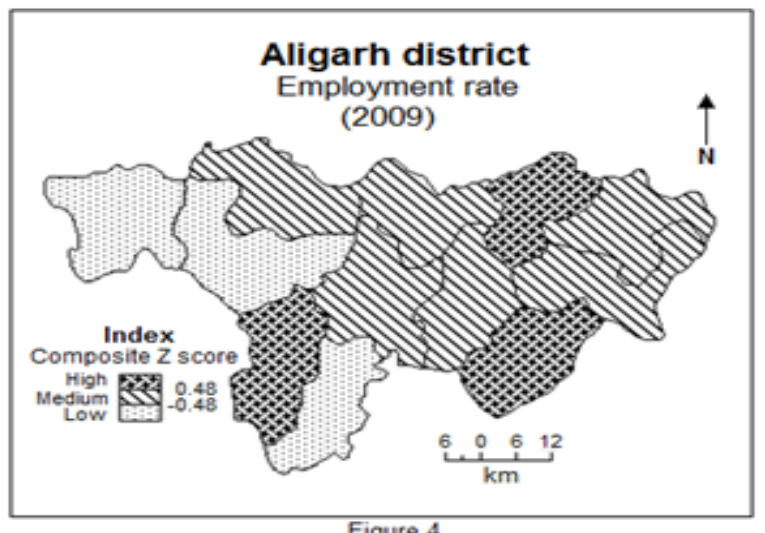

Figure 4

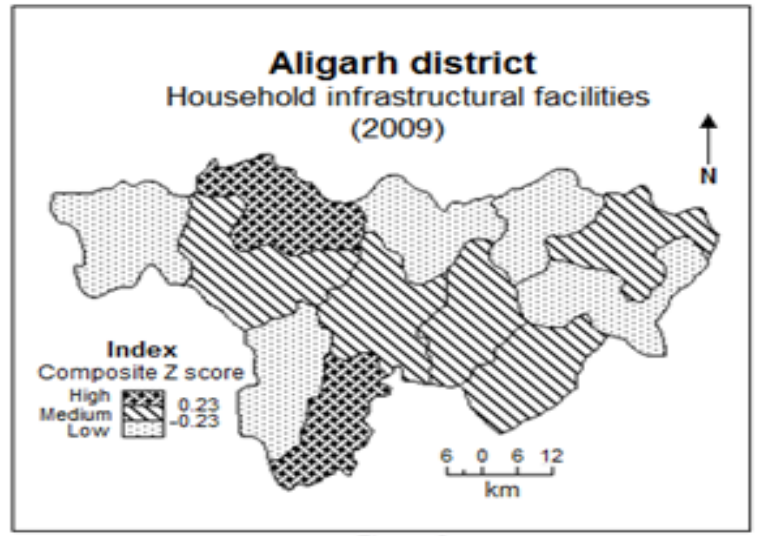

Figure 6

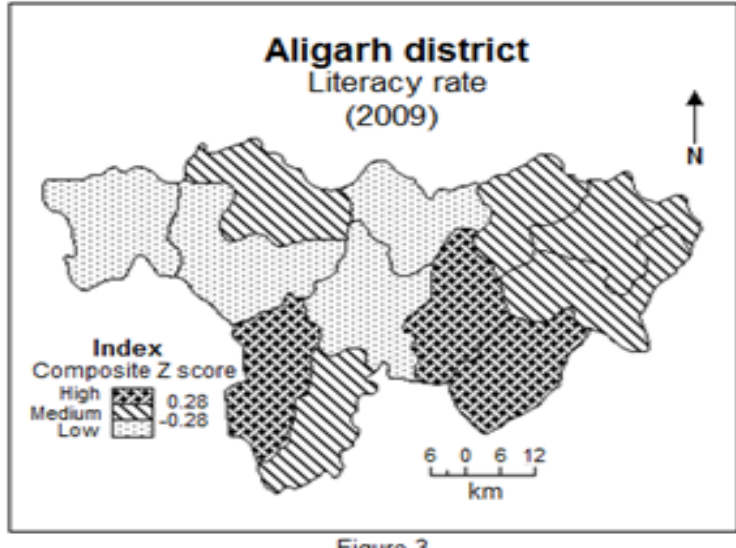

Figure 3

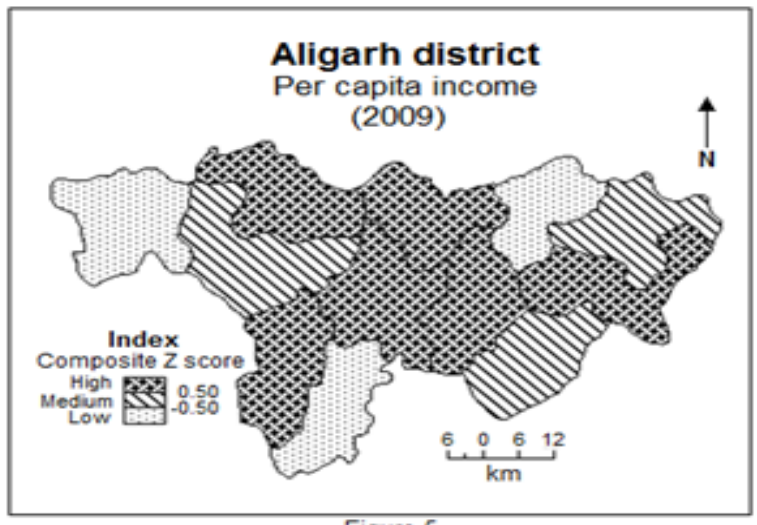

Figure 5

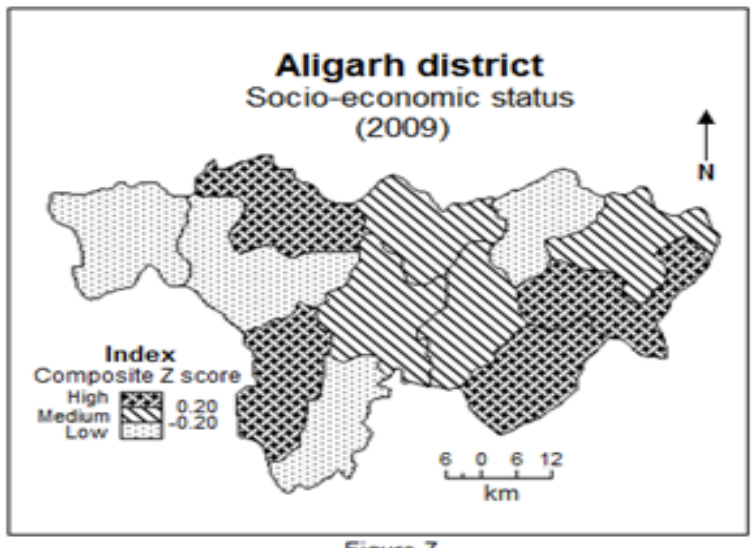

Figure 7 